To the Editors:

\title{
Association of Staphylococcus aureus nasal colonisation and mobile phone contamination in a Sri Lankan hospital
}

\author{
Ishara Karunarathna ${ }^{1}$, Nethmini Wedage ${ }^{1}$, Shamini Wickrama ${ }^{2}$, Chamara Senaratna $^{3}$, Kamani \\ Gunasekera $^{2}$
}

Ceylon Medical Journal 2020; 65: 122-123

DOI: http://doi.org/10.4038/cmj.v65i4.9285

\section{Introduction}

Staphylococcus aureus (SA) and methicillin-resistant SA (MRSA) are important nosocomial pathogens. Mobile phones (MPs) of healthcare workers (HCWs) have been shown to be contaminated, mostly with SA [1]. Evidence for an association between SA colonization of noses and MPs is available [1,2,3]. Our objectives were to determine the proportion of SA nasal colonizers and SA contaminated MPs among nurses and to verify the association between concomitant presence of SA in nares and MPs.

A cross-sectional study among nurses who used MPs at work $(n=282)$ was conducted ( $8^{\text {th }}$ January to $27^{\text {th }}$ May, 2018) at a tertiary care hospital in Colombo, Sri Lanka (excluding intensive-care, psychiatry and two surgical wards). Ethics Review Committee, University of Sri Jayewardenepura (MLS/20/17) approved this study. Simultaneously collected nasal and MP swabs were inoculated on to Mannitol Salt Agar (HiMedia, India). Colonies were confirmed as SA by Gram

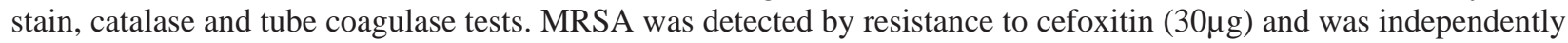
tested twice.

Hundred and nine (38.7\%) SA nasal colonizers and 54 (19.1\%) SA contaminated MPs were detected (Table 1). Of these $70.6 \%$ and $66.7 \%$ were MRSA respectively. SA and MRSA were concomitantly isolated from 31 and 15 pairs of nasal-MP swabs respectively. Harbouring nasal SA and MRSA had 2.6-fold (95\% CI 1.42, 4.75) and 2.1-fold (95\% CI 1.03, 4.37) increased odds respectively, for contamination of MPs (Table 1). Half of the nasal SA isolates was multi drug resistant (MDR) i.e. resistant to three or more classes of antibiotics.

Table 1. Isolation of Staphylococcus aureus from mobile phones and nasal swabs

\begin{tabular}{|c|c|c|c|c|}
\hline \multirow[b]{2}{*}{$\begin{array}{l}\text { Mobile phone } \\
\text { contamination }\end{array}$} & \multicolumn{4}{|c|}{ Nasal SA n (\%) } \\
\hline & $\begin{array}{l}\text { Positive } \\
(n=109)\end{array}$ & $\begin{array}{r}\text { Negative } \\
(n=173)\end{array}$ & $\begin{array}{r}\text { Total } \\
(\mathrm{n}=\mathbf{2 8 2})\end{array}$ & OR (95\% CI) \\
\hline \multicolumn{5}{|l|}{ Mobile phone SA } \\
\hline Positive & $31(28.4)$ & $23(13.3)$ & $54(19.1)$ & \\
\hline \multirow[t]{2}{*}{ Negative } & $78(71.5)$ & $150(86.7)$ & $228(80.9)$ & $2.6(1.42,4.75)$ \\
\hline & \multicolumn{4}{|c|}{ Nasal MRSA N (\%) } \\
\hline Mobile phone MRSA & $\begin{array}{r}\text { Positive } \\
(n=77)\end{array}$ & $\begin{array}{r}\text { Negative } \\
(n=205)\end{array}$ & $\begin{array}{r}\text { Total } \\
(\mathbf{n}=282)\end{array}$ & OR (95\% CI) \\
\hline Positive & 15 (19.5) & $21(10.2)$ & $36(12.8)$ & \\
\hline \multirow[t]{2}{*}{ Negative } & $62(80.5)$ & $184(89.8)$ & $246(87.2)$ & $2.1(1.03,4.37)$ \\
\hline & \multicolumn{4}{|c|}{ Nasal MSSA N (\%) } \\
\hline Mobile phone MSSA & $\begin{array}{r}\text { Positive } \\
(n=32)\end{array}$ & $\begin{array}{r}\text { Negative } \\
(n=250)\end{array}$ & $\begin{array}{r}\text { Total } \\
(\mathbf{n}=\mathbf{2 8 2})\end{array}$ & OR (95\% CI) \\
\hline Positive & $4(12.5)$ & $14(5.6)$ & $18(6.4)$ & \\
\hline Negative & $28(87.5)$ & $236(94.4)$ & 264 (93.6) & $2.4(0.74,7.82)$ \\
\hline
\end{tabular}

SA - Staphylococcus aureus MRSA - Methicillin resistant Staphylococcus aureus MSSA - Methicillin sensitive Staphylococcus aureus

${ }^{1}$ Medical Laboratory Sciences, ${ }^{2}$ Department of Microbiology, ${ }^{3}$ Department of Community Medicine, Faculty of Medical Sciences, University of Sri Jayewardenepura, Sri Lanka.

Correspondence: KG, e-mail: <kamani@sjp.ac.lk>. Received 08 September 2020 and revised version 29 November 2020 accepted 02 December 2020.

This is an open-access article distributed under the terms of the Creative Commons Attribution License, which permits unrestricted use, distribution, and reproduction in any medium, provided the original author and source are credited. 


\section{Column percentages given in parenthesis}

Medicine, gynaecology/obstetrics and surgery wards had the highest SA/MRSA nasal colonization rates (data not shown). Working in the dialysis unit was associated with a 15.4 increased risk $(95 \%$ CI 1.7,138.6) of MRSA nasal colonization. MP contamination in the dialysis unit was increased 22 fold for SA $(95 \%$ CI 2.4,202.0) and six fold for MRSA (95\% CI 1.1,32.8). MDR nasal isolates were mostly from medicine, gynaecology/obstetrics and dialysis units with a 23.5 increased risk (95\% CI 3.5,155.1) of MDR SA nasal colonization for dialysis unit HCWs (data not shown).

Nasal and MP colonization with SA/MRSA was high in this hospital and SA/MRSA nasal colonization was associated with MP contamination. Three previous studies found that $18.75 \%, 25.8 \%$ and $10.6 \%$ SA nasal colonizers had concomitant SA on MPs [1,2,3]. Chang et al demonstrated identical strains in 87.5\% (7 of 8) HCWs [3]. Similarly, 28.4\% SA nasal colonizers had concomitant SA in MPs in this study (Table 1). Molecular typing to check for identical strains was not done and is a limitation in our study.

In contrast to 6\% MRSA and 37\% MSSA nasal colonization in the past, MRSA nasal colonizers (27.3\%) were high in this study [4]. Overuse of antibiotics, disregard of standard precautions, and poor compliance with hand washing may be some of the reasons for this increase that needs to be addressed. MP contamination is high with $19.1 \%$ SA and $12.8 \%$ MRSA. In wards where standard precautions are not followed this could lead to cross contamination.

Nurses of the dialysis unit had significantly higher nasal/MP MRSA and MDR nasal isolates. Half of the nasal SA isolates were MDR which could have serious implications if a nasal colonizer was the source of an outbreak. However, this could be prevented by HCWs wearing masks and washing hands regularly. It is essential that stringent infection control practices are followed at all times.

\section{Conflicts of interest}

There are no conflicts of interest.

\section{Acknowledgments}

We thank the nurses and administrative staff of the hospital. Assistance by Ms. Saara Erathna is appreciated. Funding from University of Sri Jayewardenepura grant ASP/01/RE/MED/2017/67 is acknowledged.

\section{References}

1. Pathare NA, Asogan H, Tejani S, et al. Prevalence of methicillin resistant Staphylococcus aureus [MRSA] colonization or carriage among health-care workers. J Infect Public Health 2016; 9: 571-6.

2. Brady RR, Hunt AC, Visvanathan A et al. Mobile phone technology and hospitalized patients: a cross-sectional surveillance study of bacterial colonization, and patient opinions and behaviours. Clin Microbiol Infect 2011; 17: 830-5.

3. Chang CH, Chen SY, Lu JJ, Chang CJ, Chang Y, Hsieh PH. Nasal colonization and bacterial contamination of mobile phones carried by medical staff in the operating room. PloS One 2017; 12: e0175811.

4. Thevanesan V, Wijewardana WLK, Ekanayake EWM. Methicillin resistant Staphylococcus aureus: the scale of the problem in a Shri Lankan hospital. J Hosp Infect 1994; 26: $123-7$. 